\title{
Algunas reflexiones en torno a la dimensión jurídico- formal del proceso de constitución de cooperativas no agropecuarias en Cuba a partir del análisis del caso del municipio Pinar del Río
}

(Some reflections on the formal legal aspect of the creation of non-agricultural cooperatives in Cuba, based on analysis of the Pinar del Río case)

Orisel Hernández Aguilar ${ }^{1}$

Universidad de Pinar del Río

Sumario: I. Introducción. II. Algunas consideraciones sobre la regulación legal del proceso de constitución de las cooperativas no agropecuarias. III. Las autorizaciones para constituir cooperativas no agropecuarias. IV. Las escrituras públicas notariales de constitución de cooperativas no agropecuarias. V. La inscripción registral de las CNA. VI. A modo de conclusiones. VII. Bibliografía.

Resumen: Este artículo parte de un examen de algunos elementos generales de la regulación legal relativa al proceso de constitución de las cooperativas no agropecuarias, para, seguidamente, centrarse en tres aspectos fundamentales del mismo: las autorizaciones para constituir, las escrituras notariales de constituciones y la inscripción en el registro mercantil. Estos análisis de la forma en que se ha normado y desarrollado el proceso de constitución de las cooperativas no agropecuarias en Pinar del Río, van encaminados a determinar los aspectos jurídico-formales que ameritan perfeccionamiento.

Palabras clave: cooperativa, proceso de constitución y Derecho.

Abstract: This article begins with an exam of some general elements of the legal regulation of the process of constitution of the non agricultural cooperatives. Subsequently, it centers its attention in three fundamental aspects of the same one: the authorizations to constitute, the notarial writings

1 Máster en Derecho Constitucional y Administrativo, Profesora de Historia General del Estado y el Derecho y Derecho Romano, Departamento de Derecho, Facultad de Ciencias Sociales y Humanísticas, Universidad de Pinar del Río, Cuba. E-mail: oriselha@ upr.edu.cu 
of constitutions and the inscription in the mercantile registration. These analyses, of the way in which it has been regulated legally and developed the process of constitution of the non agricultural cooperatives in Pinegrove of the River, are guided to determine the juridical - formal aspects that requires improvement.

Key words: cooperative, constitution process and Law. 


\section{Introducción}

Los Lineamientos de la Política Económica y Social del Partido y la Revolución², aprobados por el VI Congreso del Partido Comunista de $\mathrm{Cuba}^{3}$ contienen las directrices para el perfeccionamiento del modelo socioeconómico cubano para los próximos años. En ellos figuran bajo el título de "LAS COOPERATIVAS» cinco puntos, del 25 al 29, que incluyen a estas entidades como parte de un nuevo "MODELO DE GESTIÓN ECONÓMICA» con el que el país se propone elevar la productividad del trabajo 4 .

Sobre estas bases se trabajó por parte de la Comisión Permanente de Implementación y Desarrollo de los Lineamientos hasta que, en fecha 11 de diciembre de 2012, la Gaceta Oficial de la República de Cuba en una edición extraordinaria publicó un conjunto de normas que en lo adelante constituirán, con carácter experimental, el marco jurídico para las cooperativas no agropecuarias (en lo adelante CNA). Se trata de dos Decretos-Leyes, un Decreto y dos Resoluciones. El Decreto-Ley N. ${ }^{\circ} 305$ «De las cooperativas no agropecuarias» se ocupa de sentar «las normas que regulan la constitución, funcionamiento y extinción de cooperativas en sectores no agropecuarios de la economía nacional» ${ }^{5}$. El Decreto-Ley N. ${ }^{\circ} 306$ «Del régimen especial de seguridad social de los socios de las cooperativas no agropecuarias» como su nombre indica «establece un régimen especial de seguridad social dirigido a la protección de los cooperativistas asociados en cooperativas no agropecuarias» ${ }^{6}$. El Decreto N. ${ }^{\circ} 309$

2 En lo adelante Lineamientos.

3 Vid. Lineamientos de la Política Económica y Social del Partido y la Revolución, aprobados el 18 de abril de 2012 en http://www.prensa-latina.cu/Dossiers/LineamientosVICongresoPCC.pdf

4 Hasta ese momento las regulaciones con que el ordenamiento jurídico cubano contaba en materia de cooperativas se limitaban a admitir las cooperativas en el sector agropecuario. Las normas que operaban eran, esencialmente: con carácter general el artículo 20 de la Constitución de la República de 1976 (actualizada); con carácter supletorio los artículos del 145 al 149 del Código Civil, Ley 59 de 16 de julio de 1987 (en lo adelante (C) y con carácter especial la Ley de Cooperativas de Producción Agropecuaria y de Créditos y Servicios, Ley 95 del 2 de noviembre de 2002 (en lo adelante LCPACS) y el Decreto Ley 142 de 20 de septiembre de 1993, Sobre las Unidades Básicas de Producción Cooperativa.

5 Art. 1, Decreto-Ley N. 305 «De las cooperativas no agropecuarias», Gaceta Oficial N. ${ }^{\circ} 053$ Extraordinaria de 11 de diciembre de 2012, MINJUS, La Habana, 2012, pág. 249.

6 Art. 1, Decreto-Ley N. 306 «Del régimen especial de seguridad social de los socios de las cooperativas no agropecuarias», Gaceta Oficial N. ${ }^{\circ} 053$ Extraordinaria de 11 de diciembre de 2012, MINJUS, La Habana, 2012, pág. 254. 
del Consejo de Ministros dispone el «Reglamento de las cooperativas no agropecuarias de primer grado». La Resolución N. ${ }^{\circ} 570$ del Ministerio de Economía y Planificación pone en vigor el procedimiento de licitación respecto a los bienes de un establecimiento estatal para su gestión por las cooperativas no agropecuarias y la Resolución N ${ }^{\circ} 427$ del Ministerio de Finanzas y Precios ordena las particularidades relativas a la materia tributaria, precios, normas contables, y mecanismos de financiación.

El carácter experimental que presentan estas normas apunta, en primer lugar, que se trata de una práctica sometida a estudio y posible perfeccionamiento, por ello, y en segundo orden, que se hacen mucho más importantes los estudios y reflexiones que al respecto se realicen, a fin de que la legislación definitiva que se adopte supere todas las limitaciones y fijen claras posiciones respecto a los múltiples aspectos jurídico-formales del desarrollo cooperativo cubano que hoy se encuentran en debate.

En este último sentido, conviene evaluar cómo se ha desarrollado el proceso de constitución de las CNA en su dimensión estrictamente jurídica-instrumental, que se concreta en aquellos documentos o trámites legales que lo integran, a fin de determinar los aspectos jurídico-formales que ameritan perfeccionamiento. Para tal propósito se tomarán como referencia los casos de las CNA creadas en el municipio de Pinar del Río por ser estas ejemplos típicos del fenómeno a estudiar.

\section{Algunas consideraciones sobre la regulación legal del proceso de constitución de las cooperativas}

\section{Naturaleza jurídica de la cooperativa}

La naturaleza jurídica de la cooperativa ha sido enfocada desde variadas posturas dentro de las que se pueden apuntar tres posiciones básicas: la que la considera una asociación; la que la considera una sociedad y la que la considera una categoría autónoma. ${ }^{7}$

Dentro del ordenamiento jurídico cubano, previo y posterior al Decreto-Ley 305, la cooperativa se ha concebido constitucional y civilmente como una forma de propiedad, como lo demuestra el ar-

7 Vid. GADEA, E.; SACRISTÁN, F. Y VARGAS VASSEROT, C.: Régimen jurídico de la sociedad cooperativa del siglo XXI. Realidad actual y propuestas de reforma, Dykiston SL, Madrid, 2009, pp. 70-83. 
tículo 20 del magno texto al sancionar que «Esta propiedad cooperativa es reconocida por el Estado...» y el Código Civil al ubicarla en su TÍTULO II: DERECHO DE PROPIEDAD, CAPÍTULO II: FORMAS DE PROPIEDAD, bajo la denominación de la SECCIÓN TERCERA: Propiedad cooperativa.

Sin embargo, el Artículo 2.1 del Decreto-Ley 305 reconoce a la cooperativa como "una organización con fines económicos y sociales, que se constituye voluntariamente sobre la base del aporte de bienes y derechos y se sustenta en el trabajo de sus socios» ${ }^{8}$. Esta definición de la naturaleza jurídica ha generado controversia porque resulta imprecisa para determinar exactamente qué régimen legal le confiere el legislador cubano, más aun cuando -incluso luego de la promulgación de esta normativa - las cooperativas agropecuarias siguen teniendo normas propias y un tratamiento legal distinto. Este es un aspecto nada desdeñable pues de su correcta determinación se desprenden efectos para todo el proceso de funcionamiento de las CNA, incluido el de su constitución.

\section{Tipos de CNA}

El Decreto-Ley 305 dispone que las cooperativas podrán ser de dos tipos: de primer grado y de segundo grado9. Las cooperativas de segundo grado aun no se han materializado, a pesar de que la Disposición Final Sexta del citado Decreto-Ley concedió al Consejo de Ministros el plazo de trescientos sesenta (360) días para que dictara el Reglamento para las cooperativas de segundo grado ${ }^{10}$ este aun no ha sido promulgado.

El Decreto N. 309 del Consejo de Ministros dispone el «Reglamento de las cooperativas no agropecuarias de primer grado». En el Reglamento se dispone, en su Artículo 14, que «el objeto social de la Cooperativa comprende las producciones, prestación de servicios o la actividad de comercialización, a que se dedicará de acuerdo con

8 Art. 2.1, Decreto-Ley N. ${ }^{\circ} 305$ «De las cooperativas no agropecuarias», Gaceta Oficial N. ${ }^{\circ} 053$ Extraordinaria de 11 de diciembre de 2012, MINJUS, La Habana, 2012.

9 Vid. TORGA HERNÁNDEZ, N. y RODRÍGUEZ MUSA, O.: «La cooperativa de segundo grado: perspectivas para su desarrollo en Cuba» en Boletín de la Asociación Internacional de Derecho Cooperativo, No. 48, Bilbao, 2014, pp. 81-102.

10 Artículo 5.1, Decreto-Ley N. ${ }^{\circ} 305 \ldots$ ob. Cit. 
lo que se autorice» ${ }^{11}$. Con ello quedan limitadas las cooperativas cubanas a la colocación de la producción ${ }^{12}$ y a las cooperativas de trabajo ${ }^{13}$.

Además, coincidimos con MESA TEJADA cuando señala que la aparente amplitud de opciones que parece colegirse de la lectura de la norma puede verse limitada toda vez que la autorización requerida por las CNA para constituirse viene con un pronunciamiento «en torno a la factibilidad o no del objeto social propuesto por los futuros cooperativistas» ${ }^{14}$.

Hasta el momento se han constituido en Cuba 341 cooperativas $^{15}$. Los fines fundamentales para los cuales se han autorizados son "comercio, gastronomía y servicios; construcción; transporte; industria y alimentación; y recientemente las ramas de energía y servicios contables» ${ }^{16}$.

Al clarificar esto se comprende que el proceso que se analiza seguidamente corresponde, exclusivamente, a las cooperativas de primer grado.

El proceso de constitución de las CNA

El proceso de constitución de las CNA atraviesa cinco fases fundamentales. Este proceso se regula por el Decreto-Ley 305 y por el De-

11 Decreto N. 309 del Consejo de Ministros que dispone el «Reglamento de las cooperativas no agropecuarias de primer grado». Gaceta Oficial N. 053 Extraordinaria de 11 de diciembre de 2012, MINJUS, La Habana, 2012.

12 Agrupan productores y procuran colocar los resultados de sus producciones en las mejores condiciones posibles de precio, regularidad y seguridad.

Vid. KAPLAN DE DRIMER, A. y DRIMER, B.: Las cooperativas. Fundamentos - Historia - Doctrina, Ed. Intercoop, Buenos Aires, 1981, pp. 156 y ss.

13 Reúnen a obreros, técnicos, profesionales, etc. que organizan en común su trabajo, a fin de proporcionarles fuentes de ocupación estables y convenientes.

Vid. Ibídem.

14 MESA TEJADA, N. T.: «Reflexiones críticas en torno a la regulaciones de las cooperativas no agropecuarias en Cuba» en Boletín de la Asociación Internacional de Derecho Cooperativo, No. 48, Bilbao, 2014, pp. 227-244.

15 AIN: "A declarar utilidades 290 cooperativas no agropecuarias en Cuba»(27 de enero de 2015), en Juventud Rebelde, consultado en http://www.juventudrebelde.cu/ cuba/2015-01-27/a-declarar-utilidades-290-cooperativas-no-agropecuarias-en-cuba/, en fecha 8 de abril de 2015.

16 RODRÍGUEZ DELIS, L: «Cooperativas no agropecuarias: de una experiencia a una novedad en Cuba», en Granma, 30 de abril de 2014. Consultado en http://www. granma.cu/cuba/2014-05-19/cooperativas-no-agropecuarias-de-una-experiencia-a-unanovedad-en-cuba, en fecha 18 de marzo de 2015. 
creto 309, en ambos casos las normas relativas a esta materia aparecen en sus respectivos Capítulos II.

La primera fase consiste en la presentación de la propuesta por los aspirantes a socios fundadores. En los casos previstos en el artículo 617, incisos a) y b) estos deben entregarla ante las dependencias territoriales de los órganos municipales del Poder Popular quienes trasladan, en todos los casos, a la Administración Provincial del Poder Popular que corresponda y esta a los organismos que rigen las actividades en que se proponen desarrollar las Cooperativas.

En esta fase llama la atención la indeterminación de la autoridad municipal ${ }^{18}$ encargada de recibir las propuestas, lo que supone para los interesados la necesidad de indagar al respecto por no ser la norma concluyente en su dictado.

En un segundo momento, dentro de la primera fase, para los casos referidos supra, los organismos que rigen las actividades en que se prevén enmarcar las cooperativas, presentan la propuesta con sus consideraciones a la Comisión Permanente para la Implementación y Desarrollo ${ }^{19}$.

Para los supuestos correspondientes al artículo 6 inciso c) el trámite de presentación tiene como particularidad que este se verifica directamente ante la Comisión Permanente para la Implementación y Desarrollo con indicación de la entidad estatal administradora de los bienes, su domicilio legal y actividad económica que realiza ${ }^{20}$. Se trata de una va-

17 «Las cooperativas de primer grado pueden formarse: a) A partir del patrimonio integrado por los aportes dinerarios de personas naturales que deciden voluntariamente asociarse entre sí bajo el régimen de propiedad colectiva. b) Por personas naturales que decidan voluntariamente asociarse entre sí, solo con la finalidad de adquirir conjuntamente insumos y servicios, comercializar productos y servicios, o emprender otras actividades económicas, conservando los socios la propiedad sobre sus bienes. c) A partir de medios de producción del patrimonio estatal, tales como inmuebles y otros, que se decida gestionar de forma cooperativa y para ello puedan cederse estos, por medio del arrendamiento, usufructo u otras formas legales que no impliquen la transmisión de la propiedad. d) Una combinación de las formas anteriores.», DecretoLey N. ${ }^{\circ} 305 \ldots$ ob. Cit.

18 Los Órganos Municipales del Poder Popular son la Asamblea Municipal del Poder Popular y el Consejo de la Administración Municipal.

19 Artículo 3. Decreto N. ${ }^{\circ} 309 \ldots$ ob. Cit.

20 Artículo 4. Las Cooperativas que pretendan constituirse al amparo del artículo 6, inciso c) del Decreto-Ley, los órganos locales del Poder Popular, organismos o entidades nacionales cuyas empresas o unidades presupuestadas administran los bienes en las que se prevé autorizar la gestión cooperativa, presentan la propuesta ante la Comisión Permanente para la Implementación y Desarrollo con indicación de la entidad estatal administradora de los bienes, su domicilio legal y actividad económica que realiza.

Decreto N. ${ }^{\circ} 309 \ldots$ ob. Cit. 
riante de presentación que parte más bien de la iniciativa de la Administración Pública que tiene interés en que algunas entidades estatales adopten la forma cooperativa en su gestión. En cualquier caso, el artículo 4 del Decreto 309, que alude a la forma de presentar estas propuestas, tiene una redacción que amerita una revisión gramatical, en tanto se ha incurrido, aparentemente, en errores o cambios de palabras y omisiones que afectan la claridad de las ideas, esto según el texto que figura en la Gaceta Oficial ${ }^{21}$.

En estas regulaciones es notable la ausencia de disposición sobre la forma de proceder para los casos correspondientes al artículo 6, inciso d). Siendo este apartado una combinación de las formas anteriores, resulta pertinente no dejar su tramitación a la libre interpretación de los operadores, pues resulta confuso saber, incluso, quién estaría facultado para interpretar al no existir una institución pública que tenga a su cargo el diseño y aplicación de una política nacional homogénea en materia de cooperativas ${ }^{22}$.

La segunda fase es una etapa de evaluación, durante la cual la Comisión Permanente para la Implementación y Desarrollo evalúa las solicitudes de creación de Cooperativas y con sus consideraciones presenta al Consejo de Ministros la propuesta sobre su incorporación o no a la experiencia ${ }^{23}$.

La tercera fase corresponde a la aprobación o no por el Consejo de Ministros de la propuesta de CNA.

La cuarta fase es la relativa a la comunicación de la decisión y adopción de las medidas conducentes a la creación de la cooperativa en formación ${ }^{24}$.

21 Tal vez la redacción correcta debería ser Artículo 4. En el caso de las Cooperativas que pretendan constituirse al amparo del artículo 6, inciso c) del Decreto-Ley, los órganos locales del Poder Popular, organismos o entidades nacionales cuyas empresas o unidades presupuestadas administran los bienes sobre los que se prevé autorizar la gestión cooperativa, presentan la propuesta ante la Comisión Permanente para la Implementación y Desarrollo con indicación de la entidad estatal administradora de los bienes, su domicilio legal y actividad económica que realiza. (Propuestas de cambios aparecen subrayadas)

22 Vid. RODRÍGUEZ MUSA, O.: "La autonomía cooperativa y su expresión jurídica. Una aproximación crítica a su actual implementación legal en Cuba» en Boletín de la Asociación Internacional de Derecho Cooperativo, No. 47, Bilbao, 2013, pp. 129-155.

23 Artículo 5. Decreto N. ${ }^{\circ} 309$... ob. Cit.

24 Artículo 6.1. Adoptada la decisión por el Consejo de Ministros sobre el inicio del proceso de constitución experimental de la Cooperativa a que se refiere el artículo 3 de este Reglamento, los órganos municipales del Poder Popular correspondientes informarán a los aspirantes a socios. 
En la quinta, y última fase, se desarrollan importantes acciones por parte de la Cooperativa en Formación. En primer lugar los aspirantes a socios pueden conferir mandato simple o representativo a uno o varios de ellos, o a terceros, para que gestionen, total o parcialmente, los datos, documentos y trámites necesarios para llevar adelante el proceso de constitución de la cooperativa. Cuando los designados sean varios se le denominará Comité Gestor ${ }^{25}$.

El representante o el Comité Gestor de conjunto con los órganos locales del Poder Popular, organismos o entidades nacionales a que se refieren los artículos 3 y 4 del Reglamento, realizan las evaluaciones y negociaciones correspondientes ${ }^{26}$.

Una vez concluidas estas negociaciones, la autoridad correspondiente emite su autorización de constitución —que comentaremos infra. A partir del momento que se les notifique la disposición de autorización dictada por el órgano competente tienen los socios sesenta (60) días hábiles para la constitución de la cooperativa mediante escritura pública ante notario.

El proceso de constitución culmina con la inscripción de la Cooperativa en el Registro Mercantil.

A este proceso se le reconocen dos grandes limitaciones ${ }^{27}$. De un lado está lo largo que resulta, ya que involucra múltiples entidades; y del otro está la ausencia de términos legalmente establecidos para su desarrollo 28 . Sin dudas ambos aspectos conspiran contra la motivación de las personas para emprender iniciativas de creación de CNA.

De lo expuesto queda evidenciado que en la concepción legal del proceso de constitución de las CNA, hay aspectos de índole técnico - jurídica, generales y esenciales - apuntados en la exposición realizada supra-, que ya desde el mismo texto de las normas demandan una revisión a fin de optimizar dicho proceso.

2. En el caso de las Cooperativas a que se refiere el artículo 4 del presente Reglamento, los órganos locales del Poder Popular, organismos o entidades nacionales correspondientes, informan a la entidad que administra los bienes la aprobación emitida por el Consejo de Ministros, la que lo pondrá en conocimiento de sus trabajadores.

3. Si el establecimiento o instalación estatal cuya actividad se haya aprobado gestionar de forma cooperativa se encuentra inactiva, la entidad que lo administra realiza la convocatoria de licitación que establece el artículo 9 del Decreto-Ley.

Decreto N. ${ }^{\circ} 309$... ob. Cit.

25 Artículo 8. Decreto N. ${ }^{\circ} 309 \ldots$ ob. Cit.

26 Cfr. Artículo 9 y 10. Decreto N. ${ }^{\circ} 309 \ldots$ ob. Cit.

27 Cfr. MESA TEJEDA, N.T.: ob. Cit., p. 234-235.

28 Solo se somete a término el otorgamiento de escritura pública ante notario. 


\section{Las autorizaciones para constituir CNA}

La autorización para la constitución de las CNA debe provenir de los órganos facultados ${ }^{29}$. Como disposición jurídica que es, la autorización, además de cumplir con los requisitos particulares que la norma específica dispone, debe respetar las exigencias propias de su género.

En primer lugar, se debe partir de una válida autorización emitida por medio de acuerdo previo del Consejo de Ministros de la República de Cuba, algo que figura en todos los documentos de aprobación definitiva de constitución de las CNA en Pinar del Río 30 .

En tanto documentos de carácter legal, aquellos que sancionan la constitución de las CNA deben contar con claros fundamentos jurídicos, tópico este que conviene examinar.

En las resoluciones y acuerdos emitidos por los órganos locales del Poder Popular y Ministerios se citan, generalmente, como fundamentos legales que les permiten emitir la autorización definitiva para la creación de las CNA, además de los respectivos acuerdos del Consejo de Ministros, el artículo 12.2 incisos a) y b) ${ }^{31}$ del Decreto-Ley 305, con lo cual el razonamiento jurídico se queda a medias. Este precepto explica cuales son las autoridades facultadas para dar la autorización de constitución según sea la proveniencia de los bienes o entidades sobre las que se constituyen las CNA, lo cual lo conecta con el artículo 6 , comentado supra. La sola mención del artículo 12.2 y sus incisos,

29 Artículo 11. Decreto N. ${ }^{\circ} 309 \ldots$ ob. Cit.

30 V. gr. Acuerdo N. 1454 del Consejo de Ministros de 14 de agosto de 2013 que sirve de fundamento a los Acuerdos del Consejo de Administración Provincial de Pinar del Río N. ${ }^{\circ}$ 234/ 2013, N. ${ }^{\circ} 235 / 2013$, N. ${ }^{\circ} 236 / 2013$ y N. ${ }^{\circ} 241 / 2013$, a las Resoluciones del Presidente del Consejo de Administración Provincial de Pinar del Río N. ${ }^{\circ} 8172013$, N. ${ }^{\circ} 83 / 2013,{ }^{\circ}{ }^{\circ} 85 / 2013$ y N. ${ }^{\circ} 86 / 2013$ y a la Resolución N. ${ }^{\circ} 583$ del Ministro de la Agricultura de 5 de septiembre de 2013. Acuerdo N. ${ }^{\circ} 7489$ del Consejo de Ministros de 18 de noviembre de 2013 que sirve de fundamento a la Resolución N. ${ }^{\circ}$ 105/2013 del Presidente del Consejo de Administración Provincial de Pinar del Río y a la Resolución N. ${ }^{\circ}$ 20/2014 del Ministro de Turismo.

31 Artículo 12. 2. Aprobada la propuesta por el Consejo de Ministros y cumplidos los requisitos establecidos en el Reglamento del presente Decreto-Ley, se dicta la autorización para la constitución de cada cooperativa, atendiendo a las reglas siguientes:

a) en el caso de los incisos a) y b) del artículo 6 del presente Decreto-Ley, por la máxima autoridad del organismo rector de la actividad, oído el parecer de los órganos locales del Poder Popular; y

b) en el supuesto del inciso c) del propio artículo 6, por la máxima autoridad del órgano, organismo o entidad nacional cuyas empresas o unidades presupuestadas administren los bienes, en consulta con el organismo rector cuando corresponda.

Decreto-Ley N. ${ }^{\circ} 305 \ldots$ ob. Cit. 
nada aclaran sobre la proveniencia de los bienes y de la voluntad de constitución, toda vez que al inciso a) de este artículo corresponden dos incisos distintos del artículo 6 -el a) y el b) - y al inciso b) del 12.2 le corresponde el inciso c) del artículo 6, a lo que se añade que subsiste, además, la carencia de que nada se dice sobre la entidad encargada de aprobar a las CNA que se formen según lo previsto en el artículo $6 \mathrm{~d}$ ).

En el caso de los documentos legales emitidos por el Consejo de la Administración Provincial y su Presidente en Pinar del Río estos limitan su fundamentación al citado artículo 12.2 b) del Decreto-Ley 305.

En la Resolución N. ${ }^{\circ}$ 583/2013 del Ministro de la Agricultura se hace alusión a unos sustentos legales más amplios. Esta se refiere en su segundo por cuanto a los artículos 12.2 y $13.1^{32}$ del Decreto-Ley 305 y el tercero alude al artículo $11^{33}$ del Decreto 309. No parece acertado limitar la mención del artículo 12 a su punto 2, toda vez que la clave para conferir valor legal a la decisión contenida en la Resolución estriba, en primer lugar, en la alusión al inciso pertinente. Además, la referencia al inciso a) o b) aclara a quienes consulten los registros el origen y régimen legal de los bienes que integran el patrimonio de la CNA. En el caso de la CNA de Primer Grado Ornitológica de Cuba Pinar del Río por la información que consta en el Registro Mercantil, que refieren la cuantía de los aportes dinerarios realizados por los socios y la procedencia del inmueble en que tiene su sede, se podría suponer que el fundamento de la Resolución parta del inciso a) del artículo 12.2, pero esto no resulta, en modo alguno, una fuente de certeza jurídica al respecto.

Es llamativo que en este caso en particular, la resolución haga mención al artículo 13.1 del Decreto-Ley 305 y al artículo 11 del Decreto 309, siendo que el primero de estos fija la obligación de que la disposición autorizante sea fundada y el segundo detalla los contenidos esenciales a tratar en la misma, algo que sin dudas cada actor está interpretando con mucha laxitud.

La Resolución del Ministro de Turismo por la cual se crea la CNA de Primer Grado «Café Pinar» se ampara en su tercer Por Cuanto en el ar-

32 Artículo 13.1.- La autorización de la constitución se emite mediante disposición fundada de la autoridad competente, la que contendrá las actividades de producción y servicios que se autoriza a realizar según corresponda, y cualquier otra regulación que resulte necesaria.

Decreto-Ley N. ${ }^{\circ} 305 \ldots$ ob. Cit.

33 Dispone los aspectos mínimos que debe contener la disposición que autoriza la constitución de la CNA. 
tículo $1^{34}$ y 12.2 b) del Decreto-Ley 305, en tanto el cuarto Por Cuanto ${ }^{35}$ remite a la Disposición Especial Tercera ${ }^{36}$ del citado Decreto-Ley. Si bien la referencia a la Disposición Especial es importante, dada la anterior forma en que gestionaba el local y la actividad que este realizaba, no es apreciable la utilidad de la mención del artículo 1 que apenas refiere la finalidad del Decreto-Ley 305.

Del análisis de estas disposiciones resulta evidente una falta de uniformidad y una comprensión reduccionista de los fundamentos legales que respaldan cada una de las decisiones adoptadas por las autoridades facultades. De hecho, las referencias a los artículos del Decreto-Ley 305 y el Decreto 309 debieron ser mucho más precisas y amplias para respetar el mandato de constituir documentos jurídicos correctamente fundados, toda vez que de ellos debe colegirse el tipo de CNA creado y el proceso seguido para esto.

Con respecto a los aspectos mínimos que la norma pide para este tipo de autorizaciones, debe señalarse que entre ellos figuran ${ }^{37}$ :

\section{a) El objeto social que se autoriza y el tipo de moneda en que operará}

La revisión de los objetos sociales de las CNA creadas hasta el presente en Pinar del Río evidencian una tendencia predominante hacia la prestación de servicios, pues aunque en algunos objetos sociales se intercalen algunas otras actividades, estas tienen carácter instrumental para el fin último que es de servicio ${ }^{38}$.

34 Artículo 1.-El presente Decreto-Ley tiene por objeto establecer con carácter experimental las normas que regulan la constitución, funcionamiento y extinción de cooperativas en sectores no agropecuarios de la economía nacional, en lo sucesivo cooperativas.

Decreto-Ley N. ${ }^{\circ} 305 \ldots$ ob. Cit.

35 «De conformidad con lo establecido en la Disposición Especial Tercera del precitado Decreto Ley, el mismo es aplicable a las sociedades mercantiles de capital totalmente cubano en las que se decida gestionar en forma de cooperativa su actividad». Resolución N. ${ }^{\circ}$ 20/2014 del Ministro del Turismo. Consultadas en el Registro de la Propiedad Mercantil de la Dirección Provincial del Ministerio de Justica en Pinar del Río.

36 Tercera: Lo dispuesto en el presente Decreto-Ley es de aplicación a las sociedades mercantiles de capital totalmente cubano en las que se decida gestionar de forma cooperativa su actividad.

Decreto-Ley N. ${ }^{\circ} 305 \ldots$ ob. Cit.

37 Artículo 11. Decreto N. ${ }^{\circ} 309 \ldots$ ob. Cit.

38 V. gr.: Objeto Social de la CNA de Primer Grado «Café Pinar»: prestar servicios gastronómicos, arrendar local y espacios para eventos festivos, según la capacidad y el horario de la instalación, alquiler de espacios para actividades complementarias aprobadas por el arrendador. 
De las 8 CNA que operan en el municipio Pinar del Río solo tres tienen aprobado en el acuerdo o resolución correspondiente el desarrollo de operaciones en las dos monedas (CUP y CUC). Se trata de la CNA de Primer Grado Combinado Industrial Pinar del Río, la CNA de Primer Grado Ornitológica de Cuba Pinar del Río y la CNA de Primer Grado Café Pinar. La razón puede atribuirse a que esta era la misma forma en que operaban antes de constituirse en CNA. A lo antes señalado hay que sumar que el tema de la doble moneda ha venido a ser cada vez menos importante ya que se ha extendido el uso indistinto, aun en aquellas instalaciones que antes solo operaban en CUC, del uso del CUP.

Objeto Social de la CNA de Primer Grado Combinado Industrial de Pinar del Río: producir y comercializar muebles y artículos de madera y artesanía variada y prestar servicios de reparación, restauración de mueble e inmuebles de madera, tableros, metal y servicios de pintura de mobiliario tanto en el local de trabajo como en el domicilio de los clientes.

reparación, mantenimiento y diagnósticos de equipos eléctricos y electrodomésticos; alquiler de equipos a Objeto Social de la CNA de Primer Grado Electrónica Hermanos Cruz: la población, asociado al momento y tiempo de reparación; realizar reparación ligera a instalaciones eléctricas de viviendas; realizar trabajo de información con las familias sobre el funcionamiento y mejora de equipos.

Objeto Social de la CNA de Primer Grado Taller de Reparación de Calzado «Estrella Roja»: reparación de calzado común y ortopédico, reparación de carteras, maletines y otros objetos de este tipo, además lustrado de calzado.

Objeto Social de la CNA de Primer Grado Clavel Cooperativa: ser un establecimiento gastronómico que se caracteriza por ofrecer un servicio rápido ofertando productos de lunch y otros productos de fácil elaboración así como cigarros y tabacos, caracterizándose la instalación por poseer un servicio en mostrador con banquetas (cancha), sistema de autoservicio, con mesas y sillas.

Objeto Social de la CNA de Primer Grado Ornitológica de Cuba Pinar del Río: acopiar y comercializar aves ornamentales, producir y comercializar alimentos, jaulas, medicamentos, utensilios y accesorios, además de literatura y medios necesarios para el desarrollo ornitológico, prestación de servicios veterinarios y asesorar técnica referente a la actividad ornitológica.

Objeto Social de la CNA de Primer Grado Restaurant Cielo Azul: ofertar una amplia variedad de alimentos elaborados que pueden ser producidos centralizadamente y terminados en la unidad o procesados en el propio establecimiento, donde los usuarios son atendidos en la mesa por personal con la adecuada calificación, lo cual permite combinar la necesidad de alimentación con el disfrute de comodidad; puede incluir platos de la cocina nacional y la oferta puede ser especializada o mixta sobre las bases siguientes: platos para llevar, los que pueden ser envasados y transportados sin pérdida significativa de su calidad.

Objeto Social de la CNA de Primer Grado Casa Colonial: ofertar en el restaurant una amplia variedad de alimentos elaborados que podrán ser producidos centralmente y terminados en la unidad o procesados en el propio establecimiento, en la cafetería alimentos ligeros así como cigarros y tabacos, y en el bar una oferta especializada de bebidos alcohólicas en su estado natural o en coctelería 


\section{b) Denominación de la Cooperativa, que deberá incluir el vocablo «Cooperativa»}

El tema de la adecuada denominación es, cuando menos, interesante pues, si bien se cumple con el mandato legal, es muy usual que de un documento a otro se efectúen cambios, de menor entidad, en el nombre. Así muchas de las resoluciones del Presidente del Consejo de la Administración Provincial39 de Pinar del Río van encaminadas a rectificar el nombre de las CNA, introduciendo además en la nominalización de "cooperativa» el calificativo de "no agropecuaria». Luego sucede que la escritura no los refleja exactamente ${ }^{40}$, en muchas ocasiones porque avanza en un intento de homogeneizar la denominación a la fórmula de CNA de Primer Grado «nombre». Esta búsqueda por estandarizar la nominalización termina en manos del registrador mercantil. Para ello la Dirección de los Registros de la Propiedad, Mercantil y Patrimonio del Ministerio de Justicia de la República de Cuba emitió una Indicación Metodológica, con fecha 10 de junio de $2013^{41}$ en la cual se orienta, en su anexo N. ${ }^{\circ} 1$, el uso de un Modelo de Contenido del Asiento de Inscripción de las Cooperativas no Agropecuarias de Primer Grado, en el cual la denominación social comenzará

39 En lo adelante CAP.

40 V. gr. Según al Acuerdo N. ${ }^{\circ}$ 240/2013 del CAP de Pinar del Río la CNA a constituir se denominaría Cooperativa Taller de Reparación de Calzado Estrella Roja. Este Acuerdo fue modificado por la Resolución N. ${ }^{\circ}$ 78/2013 del Presidente del CAP de Pinar del Río, quien dispuso que se denominara Cooperativa no Agropecuaria Taller de Reparación de Calzado Estrella Roja. Sin embargo, en la escritura notarial figura el nombre Cooperativa no Agropecuaria de Primer Grado Taller de Reparación de Calzado Estrella Roja.

Según la Resolución N. ${ }^{\circ}$ 105/2013 del Presidente del CAP de Pinar del Río la CNA a constituir sería la Cooperativa no Agropecuaria de Primer Grado denominada «Casa Colonial». Sin embargo, en la escritura notarial figura el nombre Cooperativa no Agropecuaria Casa Colonial.

Según al Acuerdo N. ${ }^{\circ}$ 234/2013 del CAP de Pinar del Río la CNA a constituir se denominaría Cooperativa Restaurant Cielo Azul. Este Acuerdo fue modificado por la Resolución N. ${ }^{\circ} 83 / 2013$ del Presidente del CAP de Pinar del Río, quien dispuso que se denominara Cooperativa no Agropecuaria Restaurant Cielo Azul. Sin embargo, en la escritura notarial figura el nombre Restaurant Cielo Azul Cooperativa.

Según al Acuerdo N. ${ }^{\circ}$ 241/2013 del CAP de Pinar del Río la CNA a constituir se denominaría Cooperativa Taller de Electrónica «Hermanos Cruz». Este Acuerdo fue modificado por la Resolución N. ${ }^{\circ}$ 81/2013 del Presidente del CAP de Pinar del Río, quien dispuso que se denominara Cooperativa no Agropecuaria Taller de Electrónica «Hermanos Cruz». Sin embargo, en la escritura notarial figura el nombre Cooperativa no Agropecuaria de Primer Grado Taller de Electrónica «Hermanos Cruz».

${ }^{41}$ Consultado en el Registro de la Propiedad Mercantil de la Dirección Provincial del Ministerio de Justica en Pinar del Río. 
siempre señalando que se trata de una Cooperativa no Agropecuaria de Primer Grado.

Podría creerse loable que, al menos, en última instancia el manejo de la denominación de las CNA se haya homogeneizado. Sin embargo, en el tráfico jurídico subsisten documentos que manejan de forma imprecisa los nombres de las CNA. Además, el hecho de que sea una Indicación, de dudoso valor legal fuera del Ministerio de Justicia, aunque de incuestionable peso metodológico para los Registros, quien venga a enmendar la situación, no remedia para el resto de los actores jurídicos la cuestión de la certeza respecto al nombre que deben tener las CNA.

\section{c) Nombre de las personas solicitantes y de su representante}

En todos los casos se ha sido celoso en la observancia de consignar una relación completa de los futuros cooperativistas y de aquellos que fueron seleccionados como sus representantes.

d) Inmuebles y otros bienes a arrendar o ceder en usufructo $u$ otra forma legal que no implique la transmisión de la propiedad, cuando corresponda

Respecto de este particular, en el territorio pinareño se ha recurrido como regla al arrendamiento de locales e instalaciones aledañas $y$, en algunos $\operatorname{casos}^{42}$, de otros activos fijos tangibles ${ }^{43}$.

En las disposiciones rara vez se especifican más detalles que la dirección del inmueble y nada se dice sobre el importe del contrato, salvo en el caso de la Resolución del Ministro del Turismo que autoriza a crear la CNA de Primer Grado "Café Pinar», la cual esclarece que las tarifas se regirán por las «normas regulatorias emitidas por el Ministro de Turismo el 16 de enero de $2014{ }^{44}$. Ante esta realidad, no queda

42 En el caso de la CNA de Primer Grado «Café Pinar» y la CNA de Primer Grado Casa Colonial se especifica que también serán objeto de arrendamiento activos fijos tangibles.

43 Los activos fijos tangibles, también conocidos años atrás como medios básicos, comprenden a los bienes muebles e inmuebles pertenecientes a una entidad, que poseen una vida útil superior a un año, que no se agotan en el primer uso y cuya depreciación ocurre en periodos uniformes de tiempo.

44 Resuelvo Sexto, Resolución 20/2014 del Ministro de Turismo. 
más que suponer que, con carácter posterior a la constitución de la CNA esto fuera precisado contractualmente.

En el caso de los restantes activos fijos tangibles, porque el inmueble pertenece a esta categoría, figuran referencias a ellos en el Acuerdo N. ${ }^{\circ}$ 240/2013 del CAP de Pinar del Río la CNA que da autorización para constituir la CNA de Primer Grado Taller de Reparación de Calzado Estrella Roja y en la Resolución 105/2013 del Presidente del CAP que aprueba a la CNA de Primer Grado Casa Colonial. En el primer caso se autoriza la venta de bienes esenciales para su actividad tales como las máquinas de coser, aunque sin que aparezca mención del importe. Por su parte la Resolución 105/2013 posee una lista detallada con la cantidad e importe de cada uno de los activos a arrendar.

Sobre esta cuestión puede considerar que las autorizaciones del resto de las CNA son, cuando menos, omisas pues estos bienes existían en las entidades pre-existentes que dan paso a las cooperativas y son considerados como parte del proceso de constitución según lo dispuesto en el artículo 6 c) del Decreto-Ley N. ${ }^{\circ} 305$.

Si se evalúa la Resolución 105/2013, con respecto a las precedentes emitidas a idéntico fin por la misma autoridad, puede pensarse que se trata de un progresivo perfeccionamiento técnico de los redactores, pues esta pertenece al segundo grupo de CNA que se implementaban en el territorio pinareño.

Solo en el caso del local perteneciente a la Cooperativa Ornitológica de Cuba Pinar del Río se ha dispuesto que este sea compartido por esta con la Asociación Nacional de Ornitología de Cuba en concepto de usufructo gratuito ${ }^{45}$ por tiempo ilimitado ${ }^{46}$.

\section{e) Período por el cual se va a exonerar del pago del arrendamiento, si procede}

En ningún caso de los estudiados se ha usado esta posibilidad legal, sin que medie al respecto explicación viable más que afirmar que la Administración ha hecho uso del carácter facultativo de esta disposición.

45 Según el artículo 208.1 de la Ley N. ${ }^{\circ}$ 59/1987 Código Civil cubano «El usufructo da derecho al disfrute gratuito de bienes ajenos con la obligación de conservar su forma y sustancia, a no ser que el título de su constitución o la ley autoricen otra cosa».

46 Resuelvo Primero, apartado 3, Resolución 583/2013 del Ministro de la Agricultura. 


\section{f) Medios, utensilios y herramientas a vender, cuando corresponda}

En el caso de las ventas de medios, utensilios y herramientas sucede como en el arrendamiento, es regla que se emplee como forma de transmisión de la propiedad sobre tales bienes, pero rara vez se detalla más que la descripción y la cantidad de los mismos.

Solo la Resolución que autoriza la constitución de la CNA de Primer Grado "Café Pinar» especifica que la venta se hará conforme a las «normas regulatorias emitidas por el Ministro de Turismo el 16 de enero de $2014 »{ }^{47}$ y Resolución del Presidente del CAP autorizante de la CNA de Primer Grado Casa Colonial posee una relación con la cantidad e importe de cada uno de los objetos a enajenar.

Otra cuestión que la autoridad que emite la autorización de rigor debe tener presente es la naturaleza de estos bienes ${ }^{48}$, a fin de no confundirlos con los activos fijos tangibles, de modo que no se les dé un tratamiento indistinto a bienes iguales ${ }^{49}$.

\section{g) Bienes o servicios que constituyen el pedido estatal, cuando corresponda}

Dos han sido los encargos estatales conferidos a sendas CNA en Pinar del Río. A la CNA de Primer Grado Taller de Reparación de Calzado Estrella Roja se le dio el «encargo estatal de priorizar los servicios de reparación y adaptación de calzado ortopédico, prestando especial atención a quienes lo requieran ${ }^{50}$ y a la CNA de Primer Grado Taller de Electrónica «Hermanos Cruz» se le confirió la responsabilidad de «continuar prestando servicios de reparación y mantenimiento a los equipos del Programa de Ahorro Energético» ${ }^{51}$.

Se trata en ambos casos de labores que tienen, dentro de la concepción del servicio público en Cuba, un importante nivel de sensibilidad. La reparación y adaptación del calzado ortopédico es parte de las

47 Resuelvo Octavo, Resolución 20/2014 del Ministro de Turismo.

48 Esta categoría comprende entre otros bienes a las herramientas manuales, los utensilios menores de cocina, utensilios de laboratorio, protección personal, etc., ya sea que estén en almacén o en uso.

49 V. gr. En el caso de la CNA de Primer Grado Electrónica Hermanos Cruz, en cuya autorización no hay mención de los activos fijos tangibles, sino de medios, útiles y herramientas, figura la venta de un refrigerador, un bien, que en el caso de la CNA de Primer Grado Casa Colonial le fuera arrendado como tal.

50 Acuerdo 240/2013 del CAP de Pinar del Río.

51 Acuerdo 241/2013 del CAP de Pinar del Río. 
garantías derivadas de la atención a la salud y bienestar de los ciudadanos y el Programa de Ahorro Energético, conocido como PAE, es un proyecto que procura asegurar medios eléctricos económicos para los hogares que eleven la calidad de vida de los individuos a la par que estimulen el ahorro, en beneficio de la economía doméstica y nacional.

En ninguno de los dos casos los respectivos documentos ofrecieron una fundamentación de las razones que llevan a la Administración Pública a adoptar estas decisiones. Si bien es bastante fácil para un residente en Cuba entender las posibles motivaciones que las han impulsado debe comprenderse que en el tráfico jurídico no todos los que operan lo son. Esta forma de obrar reitera, una vez más, la costumbre adquirida por disímiles actores jurídicos de la realidad nacional de minimizar la práctica de fundar sus disposiciones, con lo cual se ignora incluso, en este caso, el mandato legal del artículo 13 del Decreto-Ley 305.

\section{h) Los precios de bienes y servicios que se mantendrán centralmente establecidos, cuando corresponda}

Muy vinculado a lo que se comentaba en el apartado anterior, los precios de tales servicios se encuentran entre los que gozan de una planificación central.

En adición a ello, en la resolución que da paso a la creación de la CNA de Primer Grado "Café Pinar» se dispuso que «los productos, que se determine por la autoridad facultada, se comercializarán con arreglo al precio que tengan centralmente establecido» 52 , lo cual entraña una reserva considerable de poder, dada la generalidad de la formulación, en favor de la entidad estatal encargada de decidir al respecto.

\section{i) Insumos principales a suministrar, cuando corresponda}

En los documentos autorizantes se precisa la entidad estatal encargada de mantener los insumos necesarios para la actividad, salvo en el caso de la Cooperativa Ornitológica de Cuba Pinar del Río. Esto resulta curioso dada por la ausencia de mercados mayoristas a los que las CNA puedan dirigirse para abastecerse.

De forma general se observa que en los documentos de autorización de las CNA existen imprecisiones y manejos indistintos de algunos

52 Resuelvo Noveno, Resolución 20/2014 del Ministro de Turismo. 
de los elementos contenidos en los mismos. En este sentido las normas desarrolladoras podrían ser más específicas en cuanto a sus exigencias pero, en general, las faltas detectadas son susceptibles de mejoría con una superior preparación técnica de los operadores para enfrentar el proceso de regular una realidad nueva, como lo es la de las CNA. Es relevante recordar que el contenido de estas autorizaciones viene a serla fuente primaria, y casi en exclusiva, de precisiones sobre puntos esenciales asociados al régimen legal, seguido y a seguir, de la nueva entidad creada.

\section{Las escrituras públicas notariales de constitución de CNA}

Como primer asunto relativo a las escrituras notariales de constitución de las CNA conviene atender a un asunto de naturaleza terminológica. La relevancia de los problemas lingüísticos se hace evidente desde que se comprende que el Derecho se sirve del lenguaje para expresarse y existe sólo en el sentido que el lenguaje jurídico le da ${ }^{53}$. De ahí la necesidad de que los documentos legales, cualesquiera que estos sean, estén redactados en "un estilo claro, sobrio, conciso y unívoco» ${ }^{54}$. Esta exigencia de precisión comienza desde su denominación misma.

Si se reconoce que jurídicamente las palabras tienen un significado determinado 55 , debe evitarse a toda costa tener dos denominaciones distintas para producir el mismo efecto al amparo de las mismas normas en idénticas circunstancias. Esto no es ni lógico ni seguro para el tráfico jurídico.

Desafortunadamente, esto ha sucedido con las escrituras ${ }^{56}$ de constitución de las CNA, al menos en Pinar del Río. Aun cuando la Sección

53 Cfr. ROBLES, G.: Las reglas del derecho y las reglas de los juegos. Ensayo de teoría analítica del derecho, Palma de Mallorca, Facultad de Derecho de Palma de Mallorca, 1984 , p. 97.

54 PACHECO G., M.: Teoría del Derecho, Editorial Jurídica de Chile, Santiago de Chile, 1990, p. 714.

55 VERNENGO, R. J.: La interpretación jurídica, UNAM, México, 1977, p. 49.

56 Sólo en el caso del municipio de Pinar del Río se puede mencionar que se han otorgado cuatro Escrituras de Constitución de Cooperativa no Agropecuaria de Primer Grado, en fecha 14 de septiembre de 2013, 17 de septiembre de 2013, 24 de septiembre de 2013 y 26 de septiembre de 2013. Al mismo tiempo se han otorgado otras cuatro Escrituras Pública de Fundación de Cooperativa no Agropecuaria de Primer Grado, en fecha 19 de septiembre de 2013, 20 de septiembre de 2013, 9 de diciembre de 2013 y 5 de mayo de 2014.

Consultadas en el Registro de la Propiedad Mercantil de la Dirección Provincial del Ministerio de Justica en Pinar del Río. 
Sexta del Capítulo II del Decreto 309 se denomina, siguiendo la lógica terminológica del Capítulo, "De la escritura de constitución y la asamblea constitutiva» estas se han redactado bajo dos denominaciones: Escritura Pública de Constitución de Cooperativa no Agropecuaria de Primer Grado y Escritura Pública de Fundación de Cooperativa no Agropecuaria de Primer Grado.

Si se examinan las fechas de los instrumentos públicos en cuestión, se constata que el manejo indiferente de estas denominaciones ha sido concomitante en el tiempo y, la última de estas, es la que ha estado presente en las de más reciente otorgamiento. Esta tendencia puede atribuirse a que, como resultado del Seminario para los Notarios sobre los Requisitos Formales para la Constitución de Cooperativas de Primer Grado, de la Dirección de Notarías y Registros Civiles del Ministerio de Justicia ha circulado un documento en el cual, luego de que en su parte expositiva se afirma que la «Denominación que le corresponde a este acto jurídico (juicio de carácter técnico que realiza el notario): ESCRITURA PÚBLICA DE CONSTITUCIÓN DE COOPERATIVA DE PRIMER GRADO ${ }^{57}$ al final del mismo documento se relaciona un «Proyecto de Escritura» cuyo encabezamiento es: ESCRITURA PÚBLICA DE FUNDACIÓN DE COOPERATIVA DE PRIMER GRADO.

Todo parece indicar que esta pro-forma es incluso contraria a la voluntad de sus creadores, pero los documentos emitidos por la Dirección de Notarias y Registros Civiles siguen alimentando la contradicción. En el documento «Video-Conferencia sobre la Constitución de Cooperativas no Agropecuarias de Primer Grado», de fecha 11 de julio de 2013 se afirma -en el apartado 3-que "Se mantiene lo dispuesto en el seminario de la DNRC ${ }^{58}$ y en la proforma», no obstante, se indica que debe «agregar en la denominación y en el texto del instrumento, el término de no agropecuaria59: Escritura pública de constitución de cooperativa no agropecuaria ${ }^{60}$ de primer grado». Luego parece que la Dirección asumen que es este, en definitiva el nombre acertado para el documento notarial.

Sería esta una conclusión armonizadora si se considera que tanto la citada Indicación Metodológica de la Dirección de los Registros de la Propiedad, Mercantil y Patrimonio del Ministerio de Justicia —en su

57 Cita textual de PÉREZ DÍAZ, O. L.: Seminario para los Notarios sobre los Requisitos Formales para la Constitución de Cooperativas de Primer Grado, Dirección de Notarías y Registros Civiles del Ministerio de Justicia, $s / f$.

58 Siglas que designan a esta Dirección del Ministerio de Justicia.

59 Subrayado de la fuente original.

60 Subrayado de la fuente original. 
apartado primero- como la Instrucción No.2/013 del Viceministro de Justicia de fecha 12 de julio del 2012 —en su aparatado I.10.3- indican que el proceso de inscripción comienza con la presentación de la «escritura pública notarial de «Constitución de Cooperativa No Agropecuaria de Primer Grado». Esto evidencia la necesidad de coordinación por parte de las dos Direcciones involucradas en el proceso de constitución de las CNA a fin de uniformarlo, conforme a los dictados de su propio Ministerio.

La relevancia de este asunto no se limita a una cuestión formal, sino que de conformidad con la doctrina del notariado cubana, "uno de los juicios de mayor relevancia contenidos en un documento público es el de la calificación del acto jurídico, hecho, acto o circunstancia instrumentados» ${ }^{61}$. Además de que según el artículo 40, inciso b) de la Resolución No. 70/1992 del Director de Registros y Notarías del Ministerio de Justicia, Reglamento de la Ley de las Notarias Estatales ${ }^{62}$ es una exigencia legal que esta clasificación figure con claridad como parte del encabezamiento de los documentos notariales.

La segunda cuestión que resulta de interés dentro del ámbito de estudio de las escrituras públicas de constitución de las CNA de Primer Grado está más bien relacionada con su alcance y efectos.

Según la forma en que se regula por las normas cubanas el proceso de creación de las CNA, se puede afirmar que el instrumento público notarial tiene valor constitutivo de la persona jurídica, toda vez que según CHINEA GUEVARA esto ocurre para los tipos societarios en los que se exige como formalidad para su constitución ${ }^{63}$.

A pesar de que el actuar notarial está encaminado a dotar de fuerza pública a un acto que ya cuenta con aprobación y autorización legal, el otorgamiento de la escritura no debe limitarse solo a cumplir un mandato formal, consignando estrictamente los datos que se le presentan. En virtud del artículo 39 del Reglamento de la Ley de las Notarias Estatales el notario en la redacción de cualquiera documento debe atenerse a las intenciones de los comparecientes, indagando, hasta donde sea posible, el alcance de sus manifestaciones. Esta es la clave,

61 LORA-TAMAYO RODRÍGUEZ, I y PÉREZ GALLARDO, L. B.: «Estructura del Instrumento Público Notarial: una aproximación desde el Derecho español y el Derecho cubano», en LORA-TAMAYO RODRÍGUEZ, I y PÉREZ GALLARDO, L. B. (coordinadores): Derecho Notarial, t. II, Editorial Feliz Varela, La Habana, 2007, p. 229. 1992.

62 Gaceta Oficial N. ${ }^{\circ} 4$ Extraordinaria de 9 de junio de 1992, MINJUS, La Habana,

63 CHINEA GUEVARA, J: «La fe pública notarial en el ámbito mercantil», en LORATAMAYO RODRÍGUEZ, I y PÉREZ GALLARDO, L. B. (coordinadores): Derecho..., ob. Cit., t. III, p. 450. 
consecuente con la tradición del notariado latino, para afirmar que para cumplir a cabalidad su función, los notarios deben, en tanto garantes de la legalidad, contribuir con su desempeño a que el negocio en cuestión quede configurado con toda claridad en cada uno de sus puntos esenciales, en correspondencia con los fundamentos de Derecho que lo amparan.

Uno de los elementos que mayor atención deberían conllevar, en este sentido, son los estatutos de la nueva persona jurídica, toda vez que «formalmente escritura y estatutos forman una unidad, un único instrumento público, pues los estatutos son parte esencial de la escritura fundacional $» 64$, siendo que a los estatutos les corresponde indicar, con la mayor exactitud posible, la forma de ser y funcionar del nuevo ente creado.

Al respecto de estos instrumentos debe señalarse que, de partida, aparecen con denominaciones dispares -Estatutos de la Cooperativa no Agropecuaria de Primer Grado65; Proyecto de estatutos de la Cooperativa no Agropecuaria de Primer Grado66 - y en ocasiones no queda clara su distinción con respecto al acta de constitución ${ }^{67}$ de las CNA.

Otro tema relevante con relación a los estatutos es el hecho de que tienen un carácter casi idéntico para todas las CNA, y presentan tal grado de generalización en sus artículos que resulta difícil distinguirlo de una norma jurídica ordinaria ${ }^{68}$.

64 Ibídem, p. 452

65 V. gr.: Estatutos de la Cooperativa no Agropecuaria de Primer Grado «Café Pinar». Consultados en el Registro de la Propiedad Mercantil de la Dirección Provincial del Ministerio de Justica en Pinar del Río.

66 V. gr.: Proyecto de Estatutos de la Cooperativa no Agropecuaria de Primer Grado Electrónica Hermanos Cruz. Consultados en el Registro de la Propiedad Mercantil de la Dirección Provincial del Ministerio de Justica en Pinar del Río.

67 V. gr. Acta constitutiva y estatutos de la Cooperativa no Agropecuaria de Primer Grado Casa Colonial. Consultados en el Registro de la Propiedad Mercantil de la Dirección Provincial del Ministerio de Justica en Pinar del Río.

68 V. gr.: En materia de anticipos mensuales la regla es la abstracción, que impide determinar claramente la voluntad de los socios.

A pesar de esta regularidad, algunas diferencias se han introducido. Nótese que para la CNA Café Pinar el Presidente, el Administrador y los socios deben recibir una remuneración diferenciada, por ellos sus estatutos disponen la cuantía exacta a devengar por estos. (Artículo 45, Estatutos de la Cooperativa no Agropecuaria de Primer Grado «Café Pinar». Consultados en el Registro de la Propiedad Mercantil de la Dirección Provincial del Ministerio de Justica en Pinar del Río).

En la CNA Casa Colonial se toma como referencia para hacer la previsión la labor que realiza el socio imitando el régimen salarial. (Artículo 45, Acta constitutiva y estatutos de la Cooperativa no Agropecuaria de Primer Grado. Consultados en el Registro 
Estos aspectos, no son significativos solo por el valor jurídico-formal de los mismos, sino fundamentalmente por las consecuencias que se derivan de los mismo, toda vez que ellos son el qué y el cómo del actuar cooperativo.

Sobre la base de esta responsabilidad propia de la función notarial en el trámite de otorgamiento de la escritura de constitución el funcionario público actuante debería -al revisar los documentos presentados- en tanto como conocedor integral del Derecho, suplir las carencias de precisión legal detectadas - como las expuestas a lo largo de este artículo- a partir de la manifestación de voluntad de las partes, lo dispuesto en ley y las exigencias lógicas de la ciencia jurídica, a fin de hacer más seguro el tráfico jurídico.

Desafortunadamente la práctica de seguir indicaciones y proformas constituye hoy una causa de limitaciones en la creación notarial, con lo cual se hubiera podido en buena medida suplir carencias legales del proceso, dotando, por medio de la escritura, de claridad a cuestiones centrales del proceso de constitución que no fueron oportunamente tratadas en otros documentos legales.

\section{La inscripción registral de las CNA}

Una de las primeras medidas que se hubieron de adoptar para proceder a la inscripción de las CNA fue precisamente la creación de la Sección «Cooperativas No Agropecuarias de Primer Grado» a tenor del Artículo 45 inciso n) y 47 de la Resolución No. 230/2002 Reglamento del Registro Mercantil69, cumpliendo además el resto del articulado del Capítulo III de la propia norma ${ }^{70}$.

de la Propiedad Mercantil de la Dirección Provincial del Ministerio de Justica en Pinar del Río).

Por su parte, en la CNA Taller de Reparación de Calzado «Estrella Roja» se introdujo una modificación a los estatutos para precisar los por cientos de los ingresos mensuales del mes correspondientes al Presidente, Sustituto del Presidente, Secretario y al resto de los socios. (Artículo 43, según Escritura de Elevación a Público de Acuerdos Sociales de la Cooperativa no Agropecuaria de Primer Grado. Número: cincuenta y nueve, Pinar del Río, 4 de diciembre de 2014. Consultada en el Registro de la Propiedad Mercantil de la Dirección Provincial del Ministerio de Justica en Pinar del Río).

69 Gaceta Oficial N. ${ }^{\circ} 58$ Ordinaria de 4 de noviembre de 2002, MINJUS, La Habana, 2002.

70 Cfr. Indicación Metodológica. Dirección de los Registros de la Propiedad, Mercantil..., ob. Cit. 
Aplicando análogamente el resto de las disposiciones vigente para la tramitación registral en sede mercantil los términos se mantiene conforme al artículo 6.1 del Decreto-Ley N. ${ }^{\circ} 226$ Del Registro Mercantil ${ }^{71}$.

En cuanto a los efectos derivados del asiento en el registro, de conformidad con el artículo 14 del Decreto-Ley N. ${ }^{\circ} 305$, marca el inicio de la personalidad jurídica de la CNA notarialmente constituida.

Con respecto a esta materia el mayor cuestionamiento sea, tal vez, es el por qué no se aprovechó la oportunidad para unificar, en un solo registro, a todas las formas cooperativas existentes. Debe recordarse que ya existían previamente registros de cooperativas que se ocupa de aquellas de tipo agropecuario ${ }^{72}$. Esta duplicidad o triplicidad, sigue manteniendo la ambigüedad en torno a la naturaleza jurídica de la figura en Cuba y la falta de unidad en cuanto a la regulación y ordenación del sector cooperativo.

\section{A modo de conclusiones}

Se puede sostener que el proceso de constitución de las CNA evidencia, desde el punto de vista de la legislación que lo ordena, que es necesario un perfeccionamiento encaminado a:

- Dotar de mayor claridad y precisión a las regulaciones existentes, particularmente en materia de autoridad competente para resolver y términos para completar los trámites, y

- Armonizar las indicaciones y orientaciones que se han emitido para coadyuvar al desarrollo de dicho proceso, de manera que estas sean incorporadas, de forma sistémica en las leyes vigentes, a fin de homogeneizar la práctica y dotar a dichos mandatos de una publicidad general que permita su conocimiento por todos los posibles interesados.

Tomando en cuenta las etapas fundamentales por las que pasa el iter de constitución, se puede sostener que:

71 Gaceta Oficial N. ${ }^{\circ} 2$ Ordinaria de 10 de enero de 2002, MINJUS, La Habana, 2002.

72 Para las cooperativas la Oficina Nacional de Estadística (ONE) posee dos Registros a su cargo: el REEANE, Registro Estatal de Unidades Agropecuarias No Estatales donde se inscriben las CPA y CCS; y el REUCO, Registro de Unidades Básicas de Producción Cooperativa en que se asientan las UBPC.

Vid. FERNÁNDEZ PEISO, L.A.: El fenómeno cooperativo y el modelo jurídico nacional. Propuesta para la nueva base jurídica del cooperativismo en Cuba, tesis presentada en opción al grado científico de Doctor en Ciencias Jurídicas, Cienfuegos, 2005, p. 83. 
- En cuanto a las autorizaciones para constituir sería recomendable evaluar la posibilidad de simplificar los trámites necesarios para su aprobación y definitiva constitución,

- En lo relativo a las escrituras notariales de constitución, es preciso que se maneje una denominación uniforme para las mismas y, en cuanto a su composición sería loable sostener una posición contraria a uniformar en una proforma el trámite, toda vez que esto limita el ars notariae ${ }^{73}$ del notario, y

- En lo concerniente a la inscripción en el registro mercantil convendría evaluar la posibilidad de avanzar hacia una unificación de los registros que se ocupan de entidades de carácter cooperativo, sin distinguir por la naturaleza agraria o no de la actividad que desempeñan.

\section{Bibliografía}

Texto

AIN: «A declarar utilidades 290 cooperativas no agropecuarias en Cuba»(27 de enero de 2015), en Juventud Rebelde, consultado en http://www.juventudrebelde.cu/cuba/2015-01-27/a-declarar-utilidades-290-cooperativas-noagropecuarias-en-cuba/, en fecha 8 de abril de 2015.

CHINEA GUEVARA, J: «La fe pública notarial en el ámbito mercantil», en LoraTamayo Rodríguez, I y Pérez Gallardo, L. B. (coordinadores): Derecho Notarial, t. III, Editorial Feliz Varela, La Habana, 2007.

FERNÁNDEZ PEISO, L.A.: El fenómeno cooperativo y el modelo jurídico nacional. Propuesta para la nueva base jurídica del cooperativismo en Cuba, tesis presentada en opción al grado científico de Doctor en Ciencias Jurídicas, Cienfuegos, 2005.

GADEA, E.; SACRISTÁN, F. y VARGAS VASSEROT, C.: Régimen jurídico de la sociedad cooperativa del siglo XXI. Realidad actual y propuestas de reforma, Dykiston SL, Madrid, 2009, pp. 70-83.

KAPLAN DE DRIMER, A. y Drimer, B.: Las cooperativas. Fundamentos - Historia - Doctrina, Ed. Intercoop, Buenos Aires, 1981.

LORA-TAMAYO RODRÍGUEZ, I y Pérez Gallardo, L. B.: «Estructura del Instrumento Público Notarial: una aproximación desde el Derecho español y el Derecho cubano», en Lora-Tamayo Rodríguez, I y Pérez Gallardo, L. B.

73 Cfr. VALLET DE GOYTISOLO, J. B.: "La función notarial observada por su ciencia práctica», en Lora-TAMAYO RODRÍGUEZ, I y PÉREZ GALLARDO, L. B. (coordinadores): Derecho Notarial, t. I, Editorial Feliz Varela, La Habana, 2007, pp. 69-94. 
(coordinadores): Derecho Notarial, t. II, Editorial Feliz Varela, La Habana, 2007.

MESA TEJADA, N. T.: «Reflexiones críticas en torno a la regulaciones de las cooperativas no agropecuarias en Cuba» en Boletín de la Asociación Internacional de Derecho Cooperativo, No. 48, Bilbao, 2014, pp. 227-244.

PACHECO G., M.: Teoría del Derecho, Editorial Jurídica de Chile, Santiago de Chile, 1990.

PÉREZ DÍAZ, O. L.: Seminario para los Notarios sobre los Requisitos Formales para la Constitución de Cooperativas de Primer Grado, Dirección de Notarías y Registros Civiles del Ministerio de Justicia, s/f.

ROBLES, G.: Las reglas del derecho y las reglas de los juegos. Ensayo de teoría analítica del derecho, Palma de Mallorca, Facultad de Derecho de Palma de Mallorca, 1984.

RODRÍGUEZ DELIS, L: «Cooperativas no agropecuarias: de una experiencia a una novedad en Cuba», en Granma, 30 de abril de 2014. Consultado en http://www.granma.cu/cuba/2014-05-19/cooperativas-no-agropecuariasde-una-experiencia-a-una-novedad-en-cuba, en fecha 18 de marzo de 2015.

RODRÍGUEZ MUSA, O.: "La autonomía cooperativa y su expresión jurídica. Una aproximación crítica a su actual implementación legal en Cuba» en Boletín de la Asociación Internacional de Derecho Cooperativo, No. 47, Bilbao, 2013, pp. 129-155.

TORGA HERNÁNDEZ, N. y RODRÍGUEZ MUSA, O.: «La cooperativa de segundo grado: perspectivas para su desarrollo en Cuba» en Boletín de la Asociación Internacional de Derecho Cooperativo, No. 48, Bilbao, 2014, pp. 81-102.

VALLET DE GOYTISOLO, J. B.: «La función notarial observada por su ciencia práctica», en Lora-Tamayo Rodríguez, I y Pérez Gallardo, L. B. (coordinadores): Derecho Notarial, t. I, Editorial Feliz Varela, La Habana, 2007.

VERNENGO, R. J.: La interpretación jurídica, UNAM, México, 1977.

\section{Documentos}

Escritura de Constitución de Cooperativa no Agropecuaria de Primer Grado. Número: setecientos siete, Pinar del Río, 14 de septiembre de 2013. Consultada en el Registro de la Propiedad Mercantil de la Dirección Provincial del Ministerio de Justica en Pinar del Río.

Escritura de Constitución de Cooperativa no Agropecuaria de Primer Grado. Número: trescientos diecinueve, Pinar del Río, 17 de septiembre de 2013. Consultada en el Registro de la Propiedad Mercantil de la Dirección Provincial del Ministerio de Justica en Pinar del Río.

Escritura Pública de Fundación de Cooperativa no Agropecuaria de Primer Grado. Número: trescientos diecinueve, Pinar del Río, 19 de septiembre de 2013. Consultada en el Registro de la Propiedad Mercantil de la Dirección Provincial del Ministerio de Justica en Pinar del Río. 
Escritura Pública de Fundación de Cooperativa no Agropecuaria de Primer Grado. Número: trescientos veinte, Pinar del Río, 20 de septiembre de 2013. Consultada en el Registro de la Propiedad Mercantil de la Dirección Provincial del Ministerio de Justica en Pinar del Río.

Escritura de Constitución de Cooperativa no Agropecuaria de Primer Grado. Número: cuatrocientos cincuenta y tres, Pinar del Río, 24 de septiembre de 2013. Consultada en el Registro de la Propiedad Mercantil de la Dirección Provincial del Ministerio de Justica en Pinar del Río.

Escritura de Constitución de Cooperativa no Agropecuaria de Primer Grado. Número: setecientos cuarenta y tres, Pinar del Río, 26 de septiembre de 2013. Consultada en el Registro de la Propiedad Mercantil de la Dirección Provincial del Ministerio de Justica en Pinar del Río.

Escritura Pública de Fundación de Cooperativa no Agropecuaria de Primer Grado. Número: cuatrocientos ochenta y nueve, Pinar del Río, 9 de diciembre de 2013. Consultada en el Registro de la Propiedad Mercantil de la Dirección Provincial del Ministerio de Justica en Pinar del Río.

Escritura Pública de Fundación de Cooperativa no Agropecuaria de Primer Grado. Número: doscientos cuarenta y dos, Pinar del Río, 5 de mayo de 2014. Consultada en el Registro de la Propiedad Mercantil de la Dirección Provincial del Ministerio de Justica en Pinar del Río.

Indicación Metodológica. Dirección de los Registros de la Propiedad, Mercantil y Patrimonio del Ministerio de Justicia de la República de Cuba, La Habana, 10 de junio de 2013.

Informe de Resultados del Proyecto «Bases teóricas para la efectiva expansión jurídica de la cooperativa hacia otros sectores de la economía nacional además del agropecuario» En 2013 y 2014. Consultado en Vice-Decanato de Investigación y Posgrado de la Facultad de Ciencias Sociales y Humanísticas, Universidad de Pinar del Río.

Lineamientos de la Política Económica y Social del Partido y la Revolución, aprobados el 18 de abril de 2012 en http://www.prensa-latina.cu/Dossiers/ LineamientosVICongresoPCC.pdf

\section{Legislación}

Decreto-Ley N. ${ }^{\circ} 226$ Del Registro Mercantil, Gaceta Oficial N. ${ }^{\circ} 2$ Ordinaria de 10 de enero de 2002, MINJUS, La Habana, 2002.

Decreto-Ley N. 305 «De las cooperativas no agropecuarias», Gaceta Oficial N. ${ }^{\circ} 053$ Extraordinaria de 11 de diciembre de 2012, MINJUS, La Habana, 2012.

Decreto-Ley N. ${ }^{\circ} 306$ «Del régimen especial de seguridad social de los socios de las cooperativas no agropecuarias», Gaceta Oficial N. ${ }^{\circ} 053$ Extraordinaria de 11 de diciembre de 2012, MINJUS, La Habana, 2012.

Decreto N. ${ }^{\circ} 309$ del Consejo de Ministros que dispone el «Reglamento de las cooperativas no agropecuarias de primer grado». Gaceta Oficial N. ${ }^{\circ} 053$ Extraordinaria de 11 de diciembre de 2012, MINJUS, La Habana, 2012. 
Acuerdo N. ${ }^{\circ} 1454$ del Consejo de Ministros de 14 de agosto de 2013.

Acuerdo N. ${ }^{\circ} 7489$ del Consejo de Ministros de 18 de noviembre de 2013.

Resolución No. 230/2002 Reglamento del Registro Mercantil, Gaceta Oficial

N. 58 Ordinaria de 4 de noviembre de 2002, MINJUS, La Habana, 2002.

Resolución N. ${ }^{\circ}$ 583/2013 del Ministro de la Agricultura.

Resolución N. ${ }^{\circ}$ 20/2014 del Ministro de Turismo.

Resolución N. ${ }^{\circ}$ 81/2013 del Presidente del Consejo de Administración Provincial de Pinar del Río.

Resolución N. ${ }^{\circ}$ 83/2013 del Presidente del Consejo de Administración Provincial de Pinar del Río.

Resolución N. ${ }^{\circ}$ 85/2013 del Presidente del Consejo de Administración Provincial de Pinar del Río.

Resolución N. ${ }^{\circ}$ 86/2013 del Presidente del Consejo de Administración Provincial de Pinar del Río.

Resolución N. ${ }^{\circ}$ 105/2013 del Presidente del Consejo de Administración Provincial de Pinar del Río.

Acuerdo N. ${ }^{\circ}$ 234/ 2013 del Consejo de Administración Provincial de Pinar del Río.

Acuerdo N. ${ }^{\circ}$ 235/2013 del Consejo de Administración Provincial de Pinar del Río.

Acuerdo N. ${ }^{\circ}$ 236/2013 del Consejo de Administración Provincial de Pinar del Río.

Acuerdo N. ${ }^{\circ}$ 241/2013 del Consejo de Administración Provincial de Pinar del Río.

Instrucción No.2/013 del Viceministro de Justicia de fecha 12 de julio del 2012. 